\title{
ANEKA KREASI PRODUK OLAHAN PISANG
}

\author{
${ }^{1}$ Neti Kesumawati, ${ }^{2}$ Suryadi, ${ }^{3}$ Yukiman Armadi \\ Universitas Muhammadiyah Bengkulu \\ Corresponding author : kesumawatineti30@gmail.com
}

\begin{abstract}
ABSTRAK
Buah pisang adalah komoditas pertanian Desa Kelilik Kecamatan Kepahiang Kabupaten Kepahiang belum termanfaatkan secara maksimal, terbukti buah pisang pada umumnya masih dikonsumsi sebatas pencuci mulut sesudah makan. Padahal produksi pertanian ini sangat belimpah dan sering mengalami pembusukan akibat tidak laku terjual. Selain itu, bagian tanaman pisang lainnya, seperi jantung pisang dan bonggol pisang yang bisa diolah menjadi produk olahan juga belum diketahui masyarakat. Oleh karena itu, perlu dilakukan penyuluhan/pelatihan tentang teknologi pengolahan bagian tanaman pisang, terutama buah, jantung dan bonggol pisang untuk meningkatkan nilai tambah (nilai jual) bagian tanaman tersebut sehingga daapat meningkatkan pendapatan warga masyarakat. Salah satu teknologi yang mudah diterapkan dan biayanya sangat murah adalah mengolah buah pisang menjadi selai pisang, dodol pisang, dan kiripik pisang; mengolah jantung pisang menjadi abon jantung pisang; mengolah bonggol pisang menjadi keripik. Tujuan pengabdian masyarakat ini adalah (1) Agar warga masyarakat Desa Kelilik memiliki pengetahuan dan ketrampilan untuk memperpanjang masa simpan buah pisang dan jantung pisang; (2) Mampu mengurangi resiko kerugian akibat penumpukan hasil panen; (3) Mampu memanfaatkan teknologi pengolahan buah pisang menjadi selai pisang, dodol pisang, keripik pisang; jantung pisang menjadi abon jantung pisang; (4) Mampu meminimalisir pencemaran lingkungan akibat limabah pertanian dengan mengolah bonggol pisang menjadi keripik. Metode yang digunakan dalam pelatihan ini terdiri dari tiga metode (1) Pendidikandan penyuluhantentang arti pentingnya memperpanjang masa simpan tanaman hortikultura dan pengetahuan tentang pembuatan buah pisang dan jantung pisang serta meminimalisir pencemaran limbah bonggol pisang; (2) Pelatihan tentang proses pembuatan selai pisang, dodol pisang, keripik buah pisang, abon jantung pisang dan keripik bonggol pisang. Kegiatan pengabdian yang sudah dilakukan telah meningkatkan pendapatan warga masyarakat Desa Kelilik dalam membuat selai pisang, dodol pisang, keripik pisang, abon jantung pisang dan keripik bonggol pisang, meningkatkan nilai jual dari buah pisang, menekan kerugian ditingkat petani akibat membusuknya hasil panen, membuka peluang bisnis baru sehingga dapat meningkatkan pendapatan para petani secara umum serta meminimalisir pencemaran lingkungan akibat limbah pertanian
\end{abstract}

Kata Kunci : Buah pisang, Umur Simpan, Produk Olahan pisang. 


\section{PENDAHULUAN}

\subsection{Analilisis Situasi}

Buah pisang adalah buah yang kaya akan manfaat karena pisang mengandung kandungan gula yang lengkap, yaitu glukosa, surkosa dan fruktosa. Kandungan kalori pisang sekitar 90 kalori, kandungan kalori tersebut termasuk tinggi untuk kategori buahbuahan. Tidak sedikit orang yang menyukai buah pisang mulai dari anakanak, remaja dan orang dewasa bahkan para olahragawan banyak yang menyukai buah pisang sebagai pemulih stamina sehingga kebutuhan energy akan tergantikan setelah melakukan aktifitas olahraga (Adaninggar, 2013)

Buah pisang mempunyai potensi untuk diolah menjadi produk olahan bercita rasa khas dan mempunyai nilai jual yang cukup menjanjikan. Saat ini, produk pertanian ini sering dikonsumsi masyarakat hanya sebatas pencuci mulut sesudah makan. Padahal diversifikasi produk olahan buah pisang banyak sekali ragamnya, sepert selai pisang, dodol pisang, keripik pisang. Untuk selai pisang yang rasanya tidak kalah lezat dengan selai nanas, selai stroberi, selai pepaya, dll. Bagi yang menjalankan diet, mengkonsumsi produk olahan ini sangat baik sekali karena buah pisang mengandung serat yang tinggi dan sedikit lemak (Aida dkk, 2014). Selain itu, bagian tanaman berupa jantung pisang bisa diolah menjadi abon dan bonggol pisang bisa diolah menjadi keripik.

Desa Kelilik Kecamatan Kepahiang Kabupaten Kepahiang yang berada pada ketinggian 250-1.600 m dpl., dengan kontur berbukit, suhu rata-rata $19-29^{\circ}$ C, tingkat kelembaban nisbi 82,51\% (BPS, 2017) memiliki tanah yang cukup suburi sehingga sangat cocok untuk pertumbuhan tanaman. Kondisi ini dimanfaatkan warga masyarakat di daerah tersebut bercocok tanam tanaman pisang. Terlihat pada tahun 2016 jumlah tanaman79,574 rumpun dengan produksi 247,4 ton (BPP, 2017). Produksi yang berlimpah ini harus diantisipasi sedini mungkin agar tidak terjadi kerugian akibat pembusukan karena buah pisang termasuk tanaman hortikultura yang tidak bisa disimpan lama dan dalam struktur hidupnya masih mengalami perubahan kimiawi dan biokimiawi yang disebabkan oleh aktivitas metabolisme (Rizal, 2015).

Mengingat hal tersebut di atas, sangat perlu sekali untuk memberi penyuluhan maupun pelatihan kepada warga masyarakat yang ada di Desa Kelilik Kecamatan Kepahiang tentang pengolahan buah pisang, jantung pisang dan bonggol pisang menjadi produk olahan yang bernilai tambah atau nilai jual yang tinggi. Teknologi selai, dodol, keripik buah pisang, abon jantung pisang dan keripik bonggol pisang yang belum begitu populer di kalangan warga masyarakat merupakan produk yang menjadi prioritas untuk diberi pelatihan kepada mereka

\subsection{Rumusan Permasalahan}

a. Komoditas buah pisang dan jantung pisang merupakan komoditas yang mempunyai masa simpan pendek sehinggga sering mengalami pembusukan.

b. Komoditas buah pisang dan jantung pisang asal Desa Kelilik belum termanfaatkan secara optimal sehingga petani sering mengalami kerugian

c. Pengetahuan dan ketrampilan warga masyarakat Desa Kelilik dalam pengolahan pascapanen buah pisang menjadi produk olahan selai, dodol, keripik pisang, 
pengolahan jantung pisang menjadi abon jantung pisang masih minim

d. Warga masyarakat Desa Kelilik belum bisa memanfaatkan limbah pertanian, khususnya bonggol pisang sebagai bahan baku makanan, terutama pembuatan keripik bonggol pisang

\subsection{Target Dan Luaran}

\subsubsection{Target}

Diakhir kegiatan diharapkan warga masyarakat Kelilik Kecamatan Kepahiang memiliki pengetahuan dan ketrampilan untuk memperpanjang masa simpan buah pisang dengan mengolahnya menjadi selai, dodol, keripik pisang; mengolah jantung pisang menjadi abon jantung pisang serta meminimalisir pencemaran lingkungan dengan mengolah bonggol pisang menjadi keripik bonggol pisang; mampu mengurangi resiko pembusukan hasil panen, terutama pada saat terjadinya penimbunan hasil panen; terbukanya peluan bisnis baru

\subsubsection{Luaran}

Memberdayakan warga masyarakat Kelilik Kecamatan Kepahiang melalui penguasaan teknologi pengolahan buah pisang menjadi selai, dodol pisang,keripik pisang; pengolahan jantung pisang menjadi abon jantung pisang; dan pengolahan bonggol pisang menjadi keripik bonggol pisang

\section{METODE PELAKSANAAN}

\subsection{Solusi Permasalahan}

Buah pisangmerupakan produk unggulan yang sangat berlimpah di Desa Kelilik Kecamatan Kepahiang belum termanfaatkan secara optimal oleh warga masyarakat. Kondisi ini telah menyebabkan kerugian akibat rusak/membusuknya hasil panen. Salah satu penyebabnya adalah kurang pengetahuan dan ketrampilan masyarakat untuk dapat memperpanjang masa simpan buah pisang, seperti mengolahnya menjadi produk olahan bercita rasa khas yang dapat meningkatkan pendapatan masyarakat petani. Oleh karena itu, perlu sentuhan teknologi yang sifatnya sederhana, mudah dilaksanakan dan biayanya murah, contohnya pengolahan buah pisang menjadi selai, dodo dan kerpikl. Demikian halnya jantung pisang juga belum termanfaatkan secara optimal, dimana hanya dimanfaatkan sebagai sayuran pendamping nasi. Padahal jantung pisang pisang bisa diolah menjadi produk olahan abon jantung pisang. Selain itu, bagian tanaman yang semula dianggap limbah pertanian dan dibuang begitu saja ternyata bisa diolah menjadi keripik.

\subsection{Bentuk Kegiatan}

a. Pendidikan dan Penyuluhan

Untuk menambah wawasan warga masyarakat dilakukan penyuluhan tentang arti pentingnya memperpanjang umur buah pisang dengan mengolahnya menjadi selai, dodol dan keripik, mengolah jantung pisang menjadi abon jantung, mengolah bonggol pisang menjadi keripik bonggol pisang

b. Pelatihan

Untuk dapat meningkatkan ketrampilan dan pemahaman warga masyarakat dalam pengolahan selai pisang, dodol pisang dan keripik pisang, abon jantung pisang dan keripik bonggol pisang maka mereka diberi pelatihan 


\begin{tabular}{|c|c|c|}
\hline No & Bahan & Peralatan \\
\hline 1 & \multicolumn{2}{|c|}{ Dodol buah pisan (Prayogo, 2016) } \\
\hline & $\begin{array}{l}\text { - } 2 \text { kg buah } \\
\text { pisang } \\
\text { ambon } \\
-1 \text { butir } \\
\text { kelapa } \\
-3 \text { ons gula } \\
\text { merah } \\
-1 \text { ons tepung } \\
\text { ketan } \\
-\quad 1 / 2 \text { sendok teh } \\
\text { garam } \\
-1 \text { bungkus } \\
\text { vanili }\end{array}$ & $\begin{array}{l}\text { - Timbangan } \\
\text { - Talenan } \\
\text { - Sendok (kayu + } \\
\text { stenlis) } \\
\text { - Kompor gas } \\
\text { - Baskom } \\
\text { - Pisau } \\
\text { - Wajan } \\
\text { - Panci stenslis } \\
\text { - Cetakan dodol } \\
\text { - Gelas ukur } \\
\text { - Saringan kelapa } \\
\text { - Blender }\end{array}$ \\
\hline 2. & \multicolumn{2}{|l|}{ Selai Pisang } \\
\hline & $\begin{array}{l}\text { - } 8 \text { buah } \\
\text { pisang uk } \\
\text { sedang } \\
\text { - } 2 \text { bungkus } \\
\text { nutrisari rasa } \\
\text { jeruk } \\
\text { - } 2 \text { sdm gula } \\
\text { pasir } \\
\text { - } 1 \text { gelas air } \\
\text { putih }\end{array}$ & $\begin{array}{l}\text {-Talenan } \\
\text {-Sendok (kayu + - } \\
\text { stenlis) } \\
\text {-Kompor gas } \\
\text {-Baskom } \\
\text {-Pisau } \\
\text {-Wajan } \\
\text {-Panci stenslis } \\
\text {-Blender }\end{array}$ \\
\hline 3 & \multicolumn{2}{|c|}{ Keripik Buah Pisang } \\
\hline & $\begin{array}{l}\text { - } 2 \text { sisir pisang } \\
\text { agak matang } \\
\text { - } \text { Minyak } \\
\text { goreng } \\
\text { - } 1 \text { sdt kapur } \\
\text { - } 1 \text { liter air } \\
\text { Garam }\end{array}$ & $\begin{array}{l}\text { - Talenan } \\
\text { - Sendok (kayu + } \\
\text { stenlis) } \\
\text { - Baskom } \\
\text { Pisau } \\
\text { - Wajan } \\
\text { - Komor gas } \\
\text { - Saringan } \\
\end{array}$ \\
\hline 4 & \multicolumn{2}{|c|}{ Keripik Bonggol Pisang } \\
\hline & $\begin{array}{l}\text { - } \text { Bonggol } \\
\text { pisang } \\
\text { - } \text { Minyak } \\
\text { goreng } \\
\text {-1 sdt kapur } \\
\text {-1 liter air } \\
\text { - Garam } \\
\text {-Tepung beras }\end{array}$ & $\begin{array}{l}\text { - Talenan } \\
\text { - Sendok (kayu + } \\
\text { stenlis) } \\
\text { - Baskom } \\
\text { - Pisau } \\
\text { - Wajan } \\
\text { - Kompor gas } \\
\text { - Saringan }\end{array}$ \\
\hline
\end{tabular}

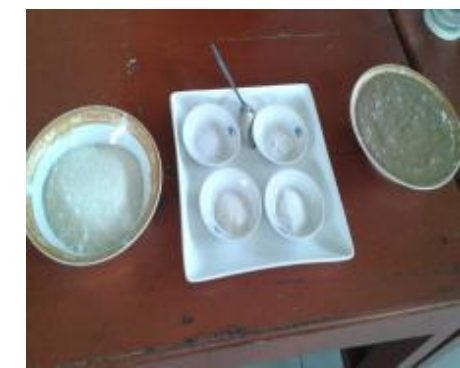

Gambar 1. Bahan selai pisang

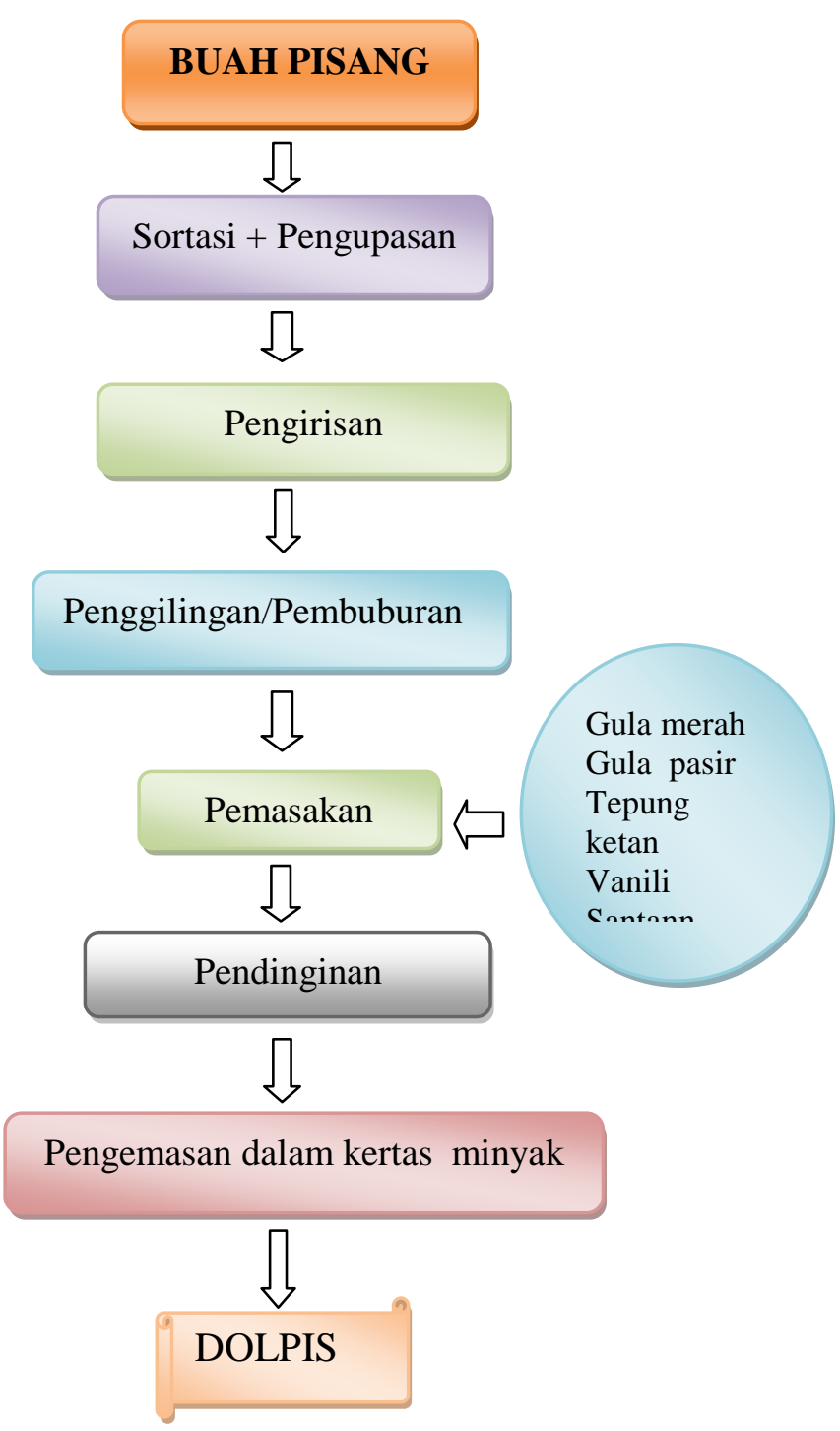

Gambar 2. Diagram alir pembuatan dolpis (dodol buah pisang) 


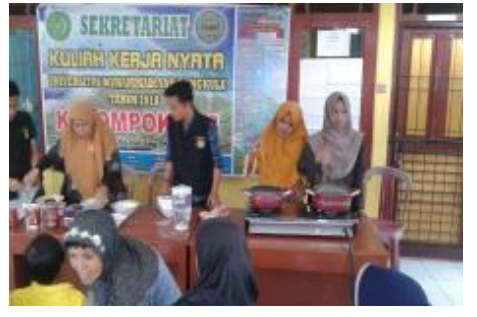

Gambar 3. Kegiatan pelatihan pembuatan produk olahan pisang

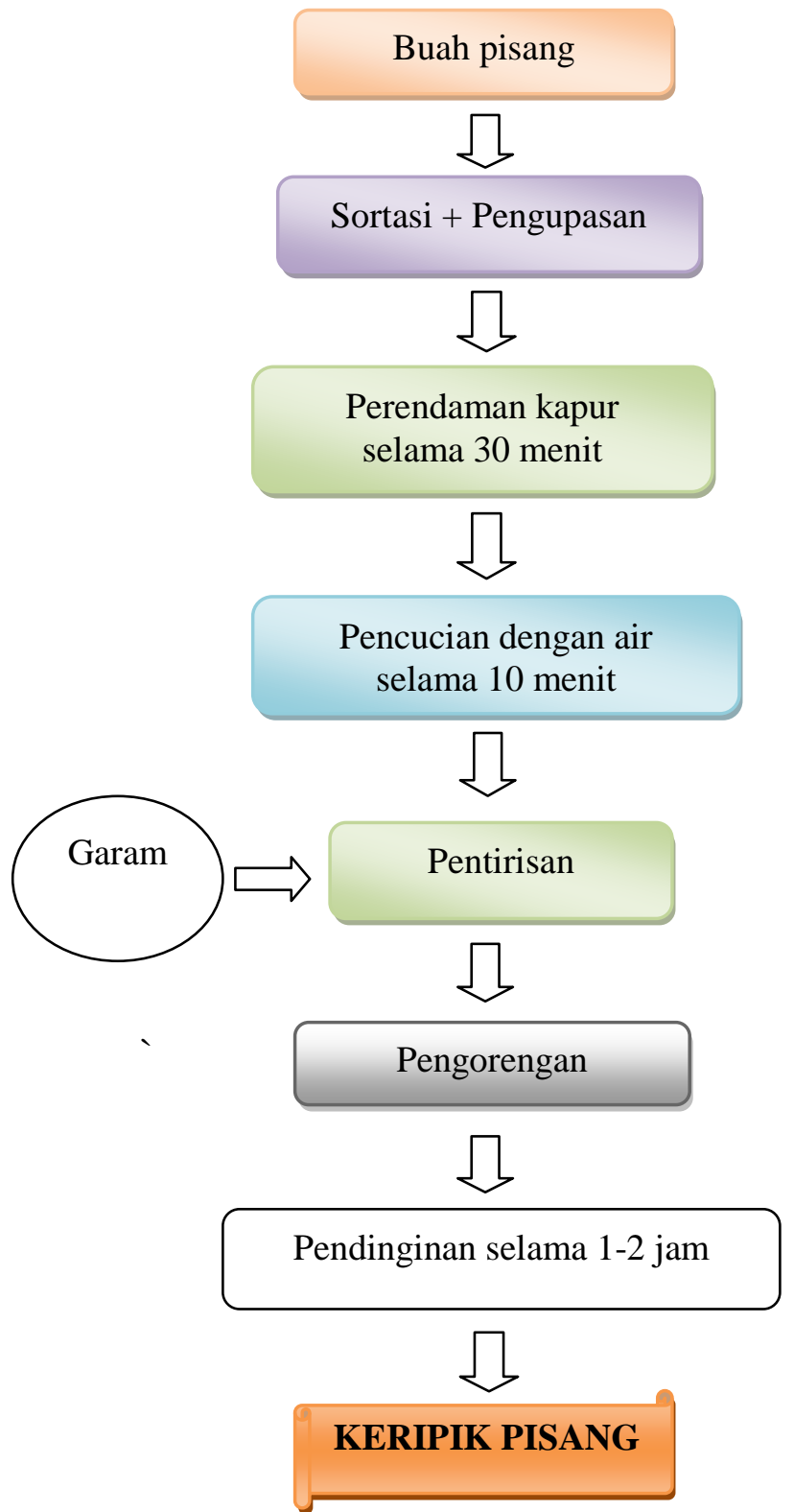

Gambar 4. Diagram alir pembuatan keripik bonggol pisang

\section{Bonggol pisang}
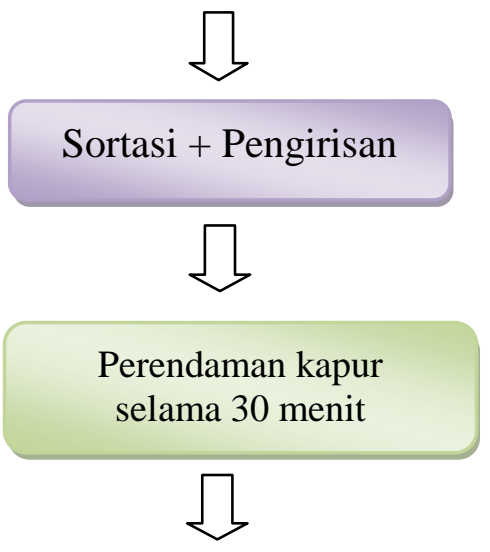

Pencucian dengan air selama 10 menit<smiles>CCCCC</smiles>

\section{Pentirisan}<smiles>C1CCC1</smiles>

\section{Pengorengan}

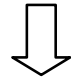

Pendinginan selama 1-2 iam<smiles>C1=CCCC1</smiles>

\section{KERIPIK BONGGOL}

PISANG

Gambar 5. Diagram alir pembuatan keripik bonggol pisang 


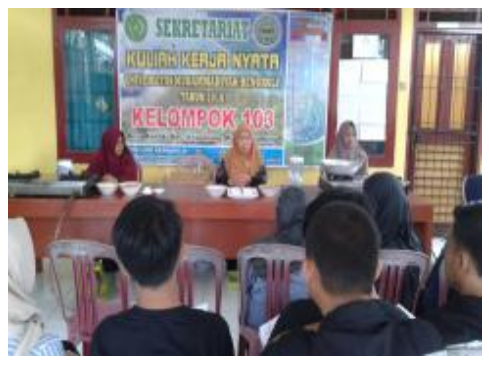

Gambar 6. Kegitan penyuluhan

\section{HASIL DAN PEMBAHASAN}

Kegiatan pengabdian masyarakat spesifik KKN melibatkan Dosen pembimbing lapangan (DPL), 2 orang Dosen Fakultas Pertanian serta para mahasiswa/i yang sedang mengikuti kegiatan KKN yang dilaksanakan Universitas Muhammadiyah Bengkulu di Desa Kelilik Kecamatan Kepahiang Kabupaten Kepahiang.

Desa Kelilik merupakan daerah penghasil buah pisang yang banyak dipasarkan di sekitar Kepahiang. Potensi SDA alam ini belum termanfaatkan secara maksimal, terbukti buah pisang banyak diperjualbelikan dalam keadaan segar. Berdasrkan kondisi inilah terbentuklah kesepakatan antara Tim penyuluh/pelatih dan warga masyarakat untuk memilih materi tentang pengolahan buah pisang menjadi produk olahan selai dan dodol, keripik; bonggol pisang menjadi keripik, jantung pisang menjadi abon..

Pada kegiatan pengabdian masyarakat ini, para mahasiswa/i KKN kelompok 103 banyak membantu pelaksanaan kegiatan, mulai dari penentuan waktu, penentuan tempat, penyusunan acara, pengurusan surat menyurat, dll. Dari segala rangkaian kegiatan yang dilakukan para mahasiswa/i, penentuan waktu merupakan kendala yang paling sulit dicari penyelesaiannya. Matapencaharian warga masyrakat yang pada umumnya sebagaian besar petani merupakan salah satu faktor yang menyebabkan susahnya mencapai titik temu penentuan waktu. Tetapi berkat kerja keras para mahasiswa/i dalam memberi pengertian betapa pentingnya mengikuti penyuluhan/pelatihan maka terselesaikan masalah ini.

Pada awal kegiatan, tim penyuluh/pelatih memberikan penyuluhan tentang arti pentingnya pengolahan buah pisang dan manfaatnya secara ekonomi serta cara pengolahan buah tomat menjadi selai pisang, keripik bonggol pisang, abon jantung pisang dan dodol pisang. secara teori. Pelaksanaan kegiatan ini bertujuan untuk lebih mempermudah pada saat demontrasi pembuatan produk tersebut di atas. Untuk demonstrasi pembuatan produk juga dilakukan beberapa tahap untuk masing-masing produk.

Dari seluruh rangkaian kegiatan penyuluhan/kegiatan pada umumnya berjalan sukses, terbukti respon warga masyarakat yang positif dan sangat antusias.

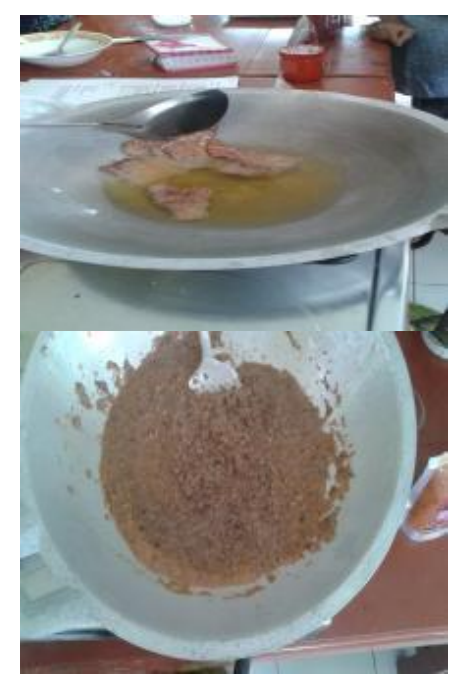

Gambar 7. Proses pembuatan abon dan keripik bonggol pisang 


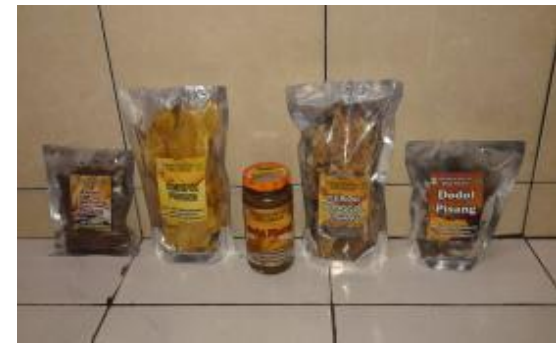

Gambar 8. Produk olahan tanaman pisang

Selanjutnya terlihat dari banyaknya pertanyaan-pertanyaan yang muncul dari para peserta, banyaknya warga masyarakat yang hadir serta didukung dengan kedatangan perangkat desa. Komunikasi antara tim penyuluh/pelatih dengan warga masyarakat selama kegiatan berjalan dirasakan sangat efektif guna mendapatkan informasi tentang pengolahan buah pisang menjadi selai dan dodol, jantung pisang menjadi abon ,bonggol pisang menjadi keripik menjadi berbagai jenis produk yang berkua

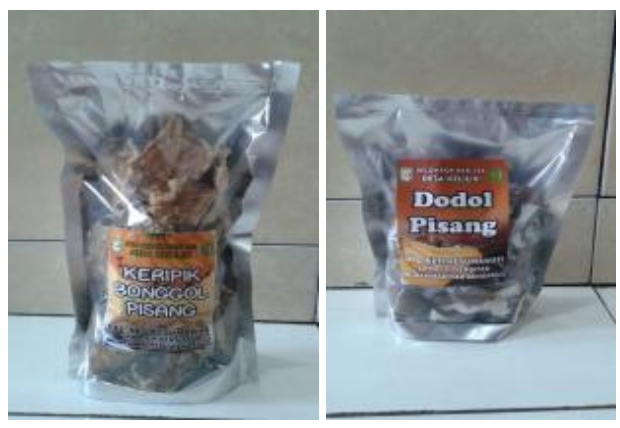

Gambar 9. Manisan dan dodol pisang

\section{SIMPULAN DAN SARAN}

\subsection{Simpulan}

7.1. Kesimpulan
1. Kegiatan pengabdian masyarakat direspon dengan baik oleh warga masyarakata Desa Kelilik terhadap semua kegiatan yang telah dirancang oleh tim penyuluh/pelatih dan mahasiswa/i KKN kelompok 103

2. Pelaksanaan kegiatan memberikan dampak positif bagi warga masyarakat Desa Kelilik dalam hal peningkatan pengetahuan dan ketrampilan pengolahan buah pisang menjadi selai dan dodol, pengolahan jantung pisang menjadi abon dan bonggol pisang menjadi keripik

3. Pelaksannan pengabdian masyarakat telah membuka pikiran warga masyarakat untuk membuka peluang bisnis produk olahan selai dan dodol pisang, produk olahan abon jantung pisang serta produk olahan keripik bonggol pisang

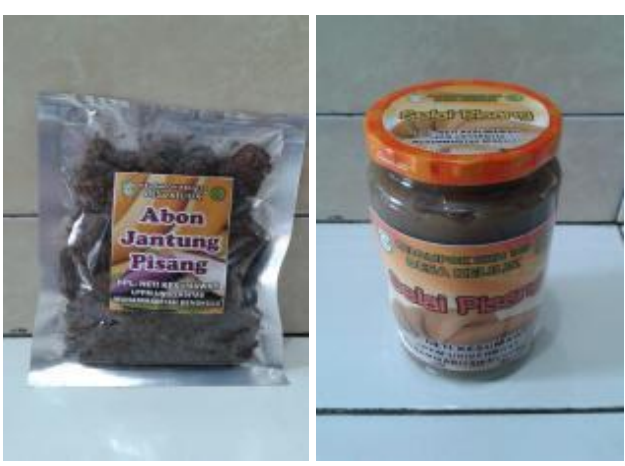

Gambar 10. Abon jantung pisang dan selai pisang

\subsection{Saran}

1. Perlu penyuluhan dan pelatihan pembuatan produk olahan seluruh bagian tanaman, seperti pelepah 
pisang menjadi kerajinan tangan, buah pisang menjadi tepung pisang, jantung pisang menjadi dendeng, dll

2. Bagi warga masyarakat yang ikut pengabdian masyarakat bisa berfungsi sebagai informan kunci dalam penyebaran pengetahuan dan ketrampilan tentang produk olahan yang bercita rasa khas Desa Kelilik

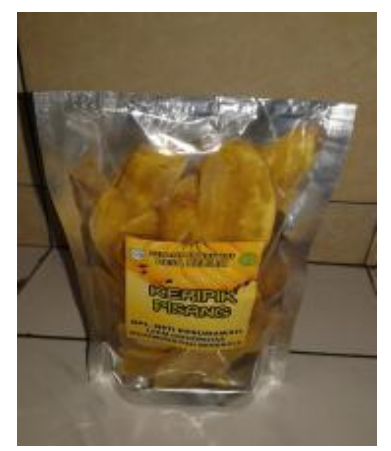

Gambar 11. Keripik bonggol pisang

\section{DAFTAR PUSTAKA}

Adaninggar, E.S., Anggraeni, M., Yulianti, N. 2013.Keripik Pisan

Rasa Dua. Usulan Program

Kreativitas Mahasiswa.

Universitas Dian Nuswantoro.

Semarang

Aida, Y., Mamuaja, F., dan Agustin, A.T. 2014. Pemanfaatan Jantung Pisang (Musa paradisiaca) Dengan Penambahan Daging Ikan Layang (Decapterus sp.) Pada Pembuatan Abon. Program Studi Ilmu Pangan Fakultas Perikanan dan Ilmu Kelautan, Universitas Sam Ratulangi.
BPS. 2017. Kabupaten Kepahyang

Dalam Angka

Rizal, M, Afrilia, Triwidyawati. 2015.

Diversifikasi Produk Olahan

Nanas Untuk Mendukung

Ketahanan Pangan di Kalimantan

Timur Balai Pengkajian

Teknologi Pertanian (BPTP)

Kalimantan Timur. Prosiing Seminar Nasional Masyarakat Biodiversitas Indondonesia. Volume 1, Nomor 8, Desember 2015 ISSN: 2407-8050 Halaman: 2011-2015 